\title{
Aprendizagem baseada em tarefas e 0 desenvolvimento da língua inglesa como segunda língua: Análises a partir da Perspectiva Ecológica.
}

\author{
Task based learning and the development of the English \\ language as a second language: Analyzes based on an \\ Ecological Perspective.
}

\section{Aprendizaje Basado en Tareas y el desarrollo de la lengua inglesa como lengua segunda: Análisis a partir de la perspectiva ecológica.}

\author{
Juarez Aloizo Lopez Junior ${ }^{1}$ \\ Vilson Leffa ${ }^{2}$ \\ Gisele Medina Nunes ${ }^{3}$ \\ Vinícius Oliveira de Oliveira ${ }^{4}$
}

\begin{abstract}
RESUMO: O objetivo deste artigo é analisar a Aprendizagem Baseada em Tarefas, mais especificamente o ciclo da tarefa, sob a perspectiva da linguística ecológica. Além disso, pretende analisar as affordances (propiciamentos) que influenciaram os caminhos tomados pelos aprendizes no desenvolvimento da língua-alvo, neste caso o inglês como segunda língua (doravante L2). Para alcançar tais objetivos, feita uma curta introdução, o presente artigo aborda a aprendizagem baseada em tarefas e, logo após, os principais pontos da perspectiva ecológica para o desenvolvimento de uma L2, concentrando-se em dois temas fundamentais de tal perspectiva: affordances e emergência. Em seguida, a metodologia do estudo é apresentada e depois os dados
\end{abstract}

\footnotetext{
1 Professor efetivo do Instituto Federal Sul Rio Grandense Campus Pelotas. Possui graduação em Letras pela Universidade Católica de Pelotas (1999) e pós-graduaçaão em nível de especialização em Tecnologias em Ensino a distância pela Universidade Cidade de São Paulo (2012). Mestre em Letras pelo Programa de Pós-Graduação em Letras da Universidade Federal de Pelotas (UFPel). Atualmente, é aluno do Programa de Pós-Graduação em Letras - Doutorado - da Universidade Católica de Pelotas (Ucpel), na área de Linguística Aplicada.

\begin{abstract}
${ }^{2}$ Vilson J. Leffa é atualmente Professor Titular da Universidade Católica de Pelotas. Doutorou-se em Linguística Aplicada pela Universidade do Texas em 1984, trabalhou na Universidade Federal do Rio Grande do Sul e foi pesquisador visitante da Universidade da Califórnia, em Irvine.
\end{abstract}

\footnotetext{
${ }^{3}$ Doutoranda na área de Linguística Aplicada com foco em feedback e aplicativos gamificados para o ensino de línguas pela Universidade Católica de Pelotas. Mestre na área de estudos da linguagem com ênfase em ensino e aprendizagem de línguas mediados pelas TIC pela Universidade Federal de Pelotas. Atua na área de ensino de Língua Inglesa em curso livre de idiomas por 12 anos como professora e também como coordenadora pedagógica.

${ }^{4}$ Possui graduação em Letras - Português e Inglês pelo Centro Universitário Franciscano (2013) e mestrado em Letras (Linguística Aplicada) pela Universidade Católica de Pelotas (2015). Atualmente é doutorando em Letras (Linguística Aplicada) pelo Programa de Pós-Graduação em Letras da Universidade Federal de Pelotas.
} 
Aprendizagem baseada em tarefas e o desenvolvimento da língua inglesa como segunda língua:

Análises a partir da Perspectiva Ecológica.

são descritos com o propósito de identificar características de um sistema complexo ecológico no ciclo da tarefa. A pesquisa constatou a presença das principais classes de interação ecológica: mutualismo, comensalismo, competição e parasitismo. A classe encontrada com mais frequência foi o mutualismo, quando os alunos se beneficiaram igualmente da interação.

PALAVRAS-CHAVE: Aprendizagem baseada em tarefas. Linguística ecológica. Ciclo da tarefa. Complexidade.

ABSTRACT: The aim of this article is to analyze Task Based Learning, more specifically the task cycle under the perspective of the Ecological Linguistics. In addition, it also aims to analyze the affordances which influenced the paths taken by the students when developing the target language, in this case English as a second language (L2). In order to reach these aims, after a short introduction, this article describes the Task Based Learning and immediately after approaches the main aspects of the ecological perspective to $L 2$ development concentrating on two specific topics: affordances and emergence. The methodology of the study is then presented and the data are described in order to identify the characteristics of a complex ecological system in the task cycle. The study identified the following classes of ecological interaction: mutualism, commensalism, competition and parasitism. The most frequent class was the mutualism when students benefit equally from the interaction.

KEYWORDS: Task based learning. Ecological linguistics. Task cycle. Complexity.

RESUMEN: El objetivo de este trabajo es analizar el Aprendizaje Basado en Tareas, específicamente el ciclo de la tarea, bajo la perspectiva de la lingüística ecológica. Además, pretendiente analizar los affordances (ofrecimientos) que influyen en los caminos tomados por los aprendices en el desarrollo de la lengua meta, en este caso el ingles como lengua segunda (en adelante L2). Para lograr estos objetivos, después de una introducción corta, este trabajo aborda el Aprendizaje Basado en Tareas y, luego después, los principales puntos de la perspectiva ecológica para el desarrollo de una L2, enfocándose en dos de sus temas fundamentales: affordances y emergencia. En seguida, la metodología del estudio es presentada y después los datos son descriptos con el propósito de identificar características de un sistema complejo ecológico en el ciclo de la tarea. La investigación constató la presencia de los principales tipos de interacción ecológica: mutualismo, comensalismo, competición y parasitismo. El tipo encontrado con más frecuencia es el mutualismo, o sea cuando los alumnos se benefician igualmente mientras interactúan.

PALABRAS CLAVES: Aprendizaje basado en tareas. Lingüística ecológica. Ciclo de la tarea. Complejidad.

\section{Introdução}

Durante o século $\mathrm{XX}$, uma das tarefas mais árduas dos linguistas aplicados foi tentar explicar como aprender uma segunda língua (doravante 
Aprendizagem baseada em tarefas e o desenvolvimento da língua inglesa como segunda língua:

L2). Várias teorias foram criadas para explicar esse fenômeno, entre elas, a Teoria Behaviorista-Estrutural, a Hipótese do Input, o Modelo da Aculturação, o Modelo da Gramática Universal, entre vários outros (PAIVA, 2014; KUMARAVADIVELU, 2006).

No entanto, até hoje não se chegou à conclusão de qual dessas teorias ou modelos melhor explicariam o fenômeno do desenvolvimento ${ }^{5}$ de uma L2. Com base nesses estudos, pode-se pensar que há evidências que o processo de desenvolvimento de uma segunda língua não ocorre de maneira linear, fato que abre caminhos para maiores pesquisas na área.

o que se defende, no parágrafo anterior, é que as teorias que consideram o processo de desenvolvimento linguístico não podem estar baseadas em uma maneira reducionista, simplificando-se esse desenvolvimento e quebrando a língua alvo em pequenas partes, sendo apresentada e praticada em "pedaços" de maneira sequencial e gradual. Essa maneira linear de abordar a aprendizagem de uma segunda língua pode ser comparada com a construção de uma parede, a qual é erguida com um tijolo por vez, sendo que os itens gramaticais considerados fáceis são colocados na base com o propósito de fornecer fundação para os itens linguísticos considerados mais difíceis.

Os aprendizes têm a tarefa de colocar os tijolos no lugar correto, primeiramente os tijolos das palavras e depois os tijolos das frases, e assim por diante. Se os tijolos da parede não forem colocados na ordem certa, a parede entrará em colapso gramatical. Esse colapso pode ser o fracasso do desenvolvimento linguístico para alguns aprendizes da língua ou a maneira estanque de aprendizado de outros (NUNAN, 1996, p. 65).

O artigo seminal de Diane Larsen-Freeman intitulado "Chaos/Complexity Science and Second Language Acquisition" (LARSEN-FREEMAN, 1997) traçou semelhanças entre o desenvolvimento linguístico de uma L2 e a teoria da

\footnotetext{
${ }^{5}$ À guisa de esclarecimento, estamos cientes da dicotomia criada por Krashen (1982), que faz a diferença entre aquisição e aprendizagem de uma L2. A opção por usar a palavra "desenvolvimento" parece mais adequada, uma vez que este artigo usa a abordagem ecológica como base teórica.
} 
complexidade/caos, tendo como objetivo buscar um novo viés teórico para a área da aquisição de uma L2. Nesse trabalho, a linguista argumenta que há muitas similaridades entre a nova ciência do caos/complexidade e a aquisição de uma L2. De acordo com Larsen-Freeman e Cameron (2008), uma abordagem complexa não se traduz automaticamente em um método complexo para o ensino de línguas. Uma das razões apresentadas pelas autoras consiste no fato de não acreditarem que um método complexo seja possível, pois o ato de limitar o professor e os aprendizes a certas técnicas ou atividades seria contrário à Teoria da Complexidade. No entanto, as autoras discutem a possibilidade do desenvolvimento de uma abordagem complexa para o ensino de línguas. Elas sugerem quatro componentes como pontos de partida úteis para a construção de uma abordagem complexa para o desenvolvimento de uma língua. São eles: a) tudo está ligado; b) a língua é dinâmica até quando está estática; c) a coadaptação é uma dinâmica chave; d) ensinar é gerenciar a dinâmica da aprendizagem.

Já para Borges e Paiva (2011), através de uma abordagem complexa de ensino de línguas, poder-se-ia integrar diversas teorias e abordagens sob um mesmo leque, abandonando o reducionismo e dogmatismo subjacente ao modo de pensar os fenômenos que ocorrem na sala de aula de língua estrangeira. Para Gaignoux e Moutinho (2016), entre as alternativas que estão em consonância com a abordagem complexa, surgiu a abordagem ecológica para tentar facilitar a compreensão do processo de desenvolvimento linguístico de uma L2.

Este artigo pretende analisar a aprendizagem baseada em tarefas, mais especificamente o ciclo da tarefa, sob a perspectiva da abordagem ecológica usando o banco de dados (aulas gravadas em vídeo) que foi criado para o desenvolvimento da dissertação de mestrado de Lopes Junior (2014) ${ }^{6}$.

\footnotetext{
${ }^{6}$ Minha pesquisa de mestrado, intitulada Aprendizagem da Língua Inglesa como Segunda Língua Baseada em Tarefas: uma proposta de trabalho com ciclo complexo (LOPES JÚNIOR, 2014) teve como objetivo analisar a abordagem de ensino da língua inglesa como segunda
} 
Também é objetivo deste artigo analisar as affordances (propiciamentos) que influenciaram os caminhos tomados pelos aprendizes nos seus desenvolvimentos da língua alvo, neste caso o inglês como L2. Para alcançar tais objetivos, primeiramente discorrer-se-á sobre a aprendizagem baseada em tarefas. Em seguida, abordar-se-ão os principais pontos da perspectiva ecológica para o desenvolvimento de uma $\mathrm{L} 2$, concentrando-se em dois temas fundamentais para tal perspectiva: affordances e emergência. Na sequência, a metodologia do estudo será exposta e logo após serão descritos os resultados das análises dos vídeos, com o propósito de identificar características de um sistema complexo ecológico no ciclo da tarefa. O artigo se encerra com as considerações finais e com indicativos de futuros caminhos de pesquisa na área.

\section{APRENDIZAGEM BASEADA EM TAREFAS}

De acordo com Willis (1996), há quatro condições que devem ser atendidas para se aprender uma língua: a) exposição à língua-alvo; b) uso dessa língua para fazer coisas; c) motivação para usar essa língua; d) foco nas formas linguísticas. Ainda, acrescentar-se-iam a essas condições o uso das affordances, criadas na sala de aula para que o desenvolvimento linguístico aconteça. Maiores detalhes serão dados sobre essa nova condição ao longo deste texto.

Por haver um grande número de definições para "tarefa", apresentam-se dificuldades para se definir tal palavra sob a perspectiva da Aprendizagem Baseada em Tarefas - ABT. Prabhu (1987) define tarefa como uma atividade que demanda que o aprendiz chegue a um resultado a partir de uma informação dada com base em um processo de raciocínio e que permita que o professor controle e regule tal processo. Para o linguista Peter Skehan (2003),

língua chamada de Aprendizagem Baseada em Tarefas ( $A B T)$ sob a perspectiva da teoria da Complexidade. 
uma razão para essa dificuldade é uma característica adicional frequentemente usada na definição de tarefas - que consiste na relação de uma tarefa com o mundo real. Long (1985) relaciona tarefas àquilo que as pessoas fazem na sua vida cotidiana, enquanto outros teóricos preferem dizer que tarefas possuem uma semelhança, direta ou indireta, com a maneira como a língua é usada. (SKEHAN, 1998)

Já Willis e Willis (2007), autores de vários livros sobre Aprendizagem Baseada em Tarefas, preferem caracterizar uma tarefa não respondendo à pergunta: "isto é uma tarefa?", mas sim respondendo quão parecida é uma atividade com uma tarefa. Para os autores citados, pode-se determinar quão parecida é uma atividade com uma tarefa fazendo as seguintes perguntas: a) a atividade capta o interesse do aprendiz? b) há um foco primário no significado? c) há um resultado? d) o sucesso é julgado em termos de resultado? e) a conclusão da atividade é a prioridade? f) a atividade relaciona-se a atividades do mundo real?

A definição de tarefa que parece ser mais adequada e usada neste trabalho é a de Skehan (1998, p. 95): "tarefa é uma atividade na qual o significado vem primeiro; há algum tipo de relacionamento com o mundo real; a sua finalização é prioridade; e a avaliação da sua realização se dá em termos de seus resultados".

A Aprendizagem Baseada em Tarefas (ABT) fornece oportunidades para um uso livre e significativo da língua-alvo, propiciando que os alunos se engajem ativamente em uma tarefa na qual a comunicação é o foco primordial para que juntos alcancem os objetivos estipulados anteriormente. Assim, essa abordagem preenche as condições para a aprendizagem da língua-alvo e busca desenvolver a interlíngua dos aprendizes, fornecendo tarefas (as quais podem ser vistas como affordances) e usando a língua para resolvê-las.

A ABT é caracterizada por três fases:

a) a pré-tarefa; 
b) o ciclo da tarefa (tarefa/planejamento do relatório/relatório);

c) o foco na língua (análise e prática).

Durante a pré-tarefa, o aluno é apresentado ao tópico que será discutido ou à tarefa. Nesse estágio, o papel do professor é introduzir o tópico e dar aos alunos instruções claras sobre o que eles terão que fazer durante a etapa da tarefa. O professor pode ajudar os alunos a lembrar de alguns itens linguísticos que possam ser úteis. A pré-tarefa pode também incluir uma gravação de pessoas realizando a tarefa. Essa atividade fornece aos alunos um claro modelo do que é esperado deles. Os alunos podem fazer anotações e passar algum tempo preparando-se para a próxima etapa: o ciclo da tarefa.

Depois de ser exposto à língua e à atividade proposta, os alunos passam para a fase mais importante dessa abordagem: o ciclo da tarefa. Essa fase é composta por três partes: tarefa, planejamento e relatório. Durante a primeira etapa, os alunos completam a tarefa em pares ou pequenos grupos usando os recursos linguísticos que possuem, enquanto o professor monitora e oferece motivação para sua realização. Nessa fase, o professor não realiza nenhuma correção. $O$ objetivo dessa etapa é a fluência e não a acurácia.

Realizada a tarefa, os alunos passam para o próximo estágio: o planejamento do relatório. Durante essa etapa, os alunos preparam um curto relatório, oral ou escrito, relatando para a turma o que foi discutido durante a tarefa. Os alunos então praticam o que eles vão dizer nos seus grupos. Enquanto os alunos planejam o relatório, o professor está disponível para que os alunos peçam conselhos ou esclarecimentos sobre quaisquer dúvidas linguísticas que porventura eles possam ter. Ao contrário da tarefa, o planejamento visa à acurácia das formas linguísticas, e por essa razão o papel do professor é o de fornecer ajuda linguística para os alunos.

Com o planejamento feito, os alunos partem para a última etapa do ciclo da tarefa: o relatório. Durante este estágio, os alunos relatam para o resto da classe os seus achados durante a tarefa. Esse relatório é preferencialmente 
oral, mas também pode ser escrito. O professor escolhe a ordem em que os alunos apresentarão seus relatórios e pode dar o feedback sobre o seu conteúdo. Nesse estágio, o professor pode também reproduzir uma gravação de outras pessoas fazendo a mesma tarefa para que os alunos comparem os seus desempenhos com os de outros alunos ou até mesmo com a performance de falantes nativos realizando a mesma tarefa.

Para finalizar, há o foco na língua. A primeira etapa é a análise, na qual o professor destaca partes relevantes das gravações usadas para que os alunos as analisem. $O$ professor pode pedir que os alunos notem características interessantes dentro desses textos. Ele pode também destacar a língua que emergiu durante a fase do relatório para análise.

Por fim, para fechar todo o ciclo, há a etapa chamada de prática. Nesta fase, o professor seleciona áreas para a prática baseada nas necessidades dos alunos e no que emergiu durante 0 ciclo da tarefa (tarefa/planejamento/relatório). Os alunos então realizam atividades direcionadas ao fortalecimento da autoconfiança e a fazer anotações sobre itens linguísticos úteis para eles.

\section{O DESENVOLVIMENTO DE UMA L2 E A ABORDAGEM ECOLÓGICA}

A linguística ecológica (LE) foi amplamente debatida na publicação de Van Lier (2004). Nesse livro o autor afirma que a LE foca na língua como relação entre as pessoas e na aprendizagem de uma língua como maneira de relacionar-se mais eficazmente com as pessoas e o mundo. Para Van Lier (2004), o conceito de affordance é crucial nessa abordagem, porque estabelece a relação entre os organismos, aprendizes e ambiente, sinalizando uma oportunidade de ação ou de inibição. Esse termo, primeiramente apresentado por Gibson no trabalho vinculado ao campo de estudo das ciências biológicas (GIBSON, 1986), significa tudo aquilo, bom ou ruim, que o ambiente fornece para o animal. $O$ termo pode ser trazido para o dia a dia: um saca 
rolha, por exemplo, pode ser visto por uma pessoa comum como um simples abridor de uma garrafa de vinho, já o psicopata, que planeja matar o seu suposto inimigo, enxerga esse mesmo instrumento como uma arma. Um outro exemplo, mas agora na área da aquisição de uma L2, é o computador com a internet e a rede mundial de computadores. Esses elementos podem ser vistos por um aprendiz da língua inglesa como affordances, as quais possibilitam a comunicação com outros falantes da língua e, por consequência, uma oportunidade para seu desenvolvimento linguístico. Já o jogador de jogos online só enxerga esses elementos como fonte de diversão. A utilidade de uma affordance é definida pela função que ela terá para um indivíduo em particular. Ainda de acordo com Gibson (1986), para uma affordance ser considerada como tal, deve-se levar em consideração a relação do animal com aquilo proporcionado pelo ambiente no qual ele está inserido, pois toda a interação entre o animal e o ambiente é única dependendo do objetivo para o qual uma affordance esteja sendo usada.

Outro conceito importante na LE é o de emergência. De acordo com Odell (1998), quando agentes trabalham individualmente em um sistema, com quase nenhuma interação, o resultado é simplesmente aquilo que foi pedido a eles. No entanto, o autor considera que algo de novo e diferente pode resultar quando agentes trabalham interagindo entre si e o meio; algo que é mais do que a soma dos resultados individuais, sendo um comportamento que tem origem das interações entre os agentes do sistema. Pode-se definir emergência como a existência de um padrão que surge da interação entre os agentes, no qual eles se organizam em um todo que é maior do que a soma das suas partes (ODELL, 1998). O todo só emerge quando há interação entre os agentes. Deve haver um número de agentes suficientes agindo paralelamente, a fim de se obter uma massa crítica. Em outras palavras, uma quantidade mínima de indivíduos é necessária em um sistema para que este possa se tornar autossustentável e que o permita crescer (ODELL, 1998). A 
soma das partes alcançam um nível superior de complexidade e não podem retornar as suas partes anteriores, uma vez que o resultado é mais do que simplesmente a sua soma.

Os conceitos de affordance e emergência podem também ser aplicados aos ambientes de aprendizagem e, no caso deste texto, no ambiente proporcionado pelo uso da ABT. Van Lier (2004) sugere a substituição da palavra input por affordance, evidenciando a importância que o conceito apresenta. Essa importância também se revela no caso da ABT, onde o ambiente criado pelo ciclo da tarefa tem como objetivo promover affordances que propiciem a emergência de oportunidades de desenvolvimento da interlíngua do aluno lá inserido. Como já demonstrado na pesquisa de Lopes Junior (2014), o ciclo da tarefa pode ser caracterizado como um sistema adaptativo complexo e, assim, a emergência deve ser vista como um conceito importante.

De acordo com Larsen-Freeman (1997), a língua pode ser considerada um sistema adaptativo complexo, o qual emerge bottom-up, isto é, a partir das interações entre os agentes da comunidade linguística. Sendo assim, para a criação de um sistema complexo na sala de aula seria ideal que a emergência fosse imprevisível, que o sistema usasse uma regra de baixo para cima (bottom up), ao invés de cima para baixo (top down). Em outras palavras, que as necessidades e desejos de aprendizagem emergissem a partir dos alunos (bottom) e não do professor (top). Apesar da ideia de que melhor fosse usar a abordagem bottom up, tem-se a considerar que podem surgir problemas com os agentes, que são os alunos, pois eles poderiam usar a mesma estrutura que tenha emergido anteriormente, propiciando a repetição e a não progressão no seu desenvolvimento linguístico, resultando em fossilização. Assim, se na aprendizagem com a abordagem bottom up se identificar que os alunos estão incorrendo em repetições das estruturas linguísticas, deve-se inverter essa ordem e fazer uso do top down, a fim de tentar evitar-se esse comportamento, 
especialmente em situações de ensino que se deseja um produto final. Com isso, os alunos serão guiados para que estruturas desejadas emerjam.

A abordagem ecológica, assim como a abordagem complexa, não considera a aquisição de uma língua como um sistema gradual e linear, mas como a emergência de um novo sistema complexo de significação (VAN LIER, 2004). Kramsch (2008) concorda quando diz que os professores de uma segunda língua não ensinam códigos linguísticos, mas significados.

Vários linguistas se aventuraram pela selva da abordagem ecológica, talvez entre os mais dedicados a esta área estejam Leo van Lier (2000, 2004, 2010), Claire Kramsch (2008) e Kramsch e Whiteside (2008). Outra autora que explorou essa área foi Paiva (2013). Para ela, vive-se em biomas, em comunidades ecológicas, que são definidas como um grupo de espécies interagindo de forma real ou potencial em um mesmo local. Se quiser crescer e se reproduzir em seus biomas, precisa-se de alguns recursos, e a língua pode ser vista como tal. Para Leffa (2003), ninguém aprende sozinho, como também ninguém cresce, vive, sofre ou morre sozinho; o ser humano está sempre agindo e reagindo com o contexto que o cerca. A aprendizagem, neste caso da língua inglesa como L2, acontece no lugar onde as affordances estejam presentes, a fim de possibilitar a emergência de oportunidades, nas quais os aprendizes possam interagir por meio de novas experiências linguísticas. A ABT tem como objetivo criar um espaço onde o desenvolvimento linguístico ocorra com tais características.

Este artigo, além de apoiar-se nos trabalhos de Van Lier (2000, 2004, 2010), toma como base teórica Paiva (2013). Nesse trabalho, a linguista relaciona a interação da sala de aula com a interação de determinadas espécies em um bioma. Tais interações serão resumidas a seguir.

Quando se leva em conta a interação entre espécies, há quatro classes diferentes de interação: mutualismo (quando as duas espécies se beneficiam da interação); comensalismo (uma espécie se beneficia e a outra não é 
prejudicada); competição (cada espécie é afetada negativamente) e parasitismo (uma espécie se beneficia e a outra fica em desvantagem).

Quando se está no campo podem-se visualizar aves em cima de bois. Elas estão se alimentando dos carrapatos que vivem nesses animais. Enquanto o boi livra-se desses hóspedes inconvenientes, os pássaros se alimentam. Esse é um exemplo de mutualismo na natureza. Já o comensalismo, pode ser verificado quando os abutres ficam à espreita esperando que os carnívoros se alimentem. Quando um leão, por exemplo, dá-se como saciado, essas aves se alimentam da carcaça e dos restos deixados por eles. Seres vivos competem entre si por recursos, algumas plantas quando estão muito próximas podem competir pela água ou até pela luz. Ainda usando o primeiro exemplo, ao observar a situação sob o ponto de vista do carrapato e o boi, pode-se constatar o parasitismo, pois somente o carrapato se beneficia dessa interação, prejudicando o boi ao sugar seu sangue. Não é por menos que carrapatos são chamados de parasitas.

Pressupõe-se que todas essas formas de interação podem ser vistas na sala de aula de língua inglesa como $L 2$ usando a $A B T$, sendo o objetivo deste texto abordar tais interações.

\section{METODOLOGIA}

Esta seção do artigo visa apresentar o contexto de pesquisa, os sujeitos analisados, os dados que foram coletados, o instrumento empregado para a coleta dos dados e os procedimentos adotados para a sua análise.

Faz-se importante, ainda, informar 0 uso de uma perspectiva metodológica etnográfica no desenvolvimento desta coleta de dados. Esse modelo de pesquisa foi escolhido tendo em vista que a etnografia é o estudo do comportamento das pessoas em contextos naturais e dinâmicos, com foco especial na interpretação cultural do comportamento (WATSON-GEGEO, 1995). Considerando diversas formas de se pesquisar a educação, a etnografia mostra- 
se uma alternativa bastante significativa de pesquisa, tendo em vista que permite lidar com questões relativas à teoria e à prática.

A vantagem da etnografia para a pesquisa em L2 está na ênfase holística, na descrição densa e nas análises das interações entre professores e aprendizes e nos vários níveis de contextos em que essas interações ocorrem (WATSON-GEGEO, 1995). Além disso, métodos de pesquisa qualitativos, como o etnográfico, parecem servir para a compreensão da língua como um sistema dinâmico complexo (LARSEN-FREEMAN; CAMERON, 2008).

\subsection{Contexto da pesquisa}

Com base no referencial teórico-metodológico citado anteriormente, observamos um grupo de estudantes de faixa etária semelhante - entre 20 e 25 anos - durante a execução de um ciclo completo da tarefa, em uma sala de aula de um curso de inglês como L2. Os alunos foram expostos à Aprendizagem Baseada em Tarefas e analisamos se as características de uma comunidade ecológica, citadas anteriormente, poderiam ser identificadas durante o ciclo da tarefa.

As aulas foram ministradas no nível B1 do Quadro Europeu Comum de Referências para Línguas (QECRL). Este nivelamento é utilizado com grande abrangência na Europa e em outros países, e demonstra em seis níveis (A1, A2, B1, B2, C1 e C2) a proficiência do aprendiz nas habilidades de escrita, escuta, leitura e fala, sendo essa última o foco desta investigação.

Com base no QECRL, um aluno proficiente na habilidade de fala no nível B1, o qual se refere ao nível usuário independente (conhecido também como pré-intermediário), deve ser capaz de entender os principais pontos de um input padrão e sobre questões familiares ao aprendiz e que são frequentemente encontradas no trabalho, escola ou em atividades de lazer. Deve ser capaz de lidar com a maioria das situações que são prováveis de surgir enquanto viaja em uma área onde a língua é falada. Pode também produzir textos simples 
sobre tópicos familiares a ele ou de seu interesse pessoal. Por fim, um aluno proficiente pode descrever experiências, eventos, sonhos, esperanças e ambições e dar breves razões para suas opiniões e planos.

\subsection{Os sujeitos}

Em relação aos sujeitos usados na pesquisa, o grupo foi composto por jovens adultos, estudantes de nível de pós-graduação da Universidade Federal de Pelotas no ano de 2013.

Seguindo o conteúdo programático desenvolvido durante esse curso, o objetivo era que os participantes desenvolvessem as funções linguísticocomunicativas descritas no nível B1 do QECRL, uma vez que o material utilizado em sala de aula tem como objetivo habilitar os alunos a serem proficientes neste nível.

\subsection{Procedimentos}

Os dados usados para a análise foram provenientes de todas as interações entre os participantes da pesquisa durante o ciclo da tarefa. Essas interações aconteceram durante a aplicação da Aprendizagem Baseada em Tarefas em uma sala de aula de inglês como língua estrangeira.

Uma vez que esta pesquisa possui o caráter etnográfico, o professor fez parte da pesquisa e assumiu seus diferentes papéis durante o ciclo da tarefa. Para tornar a coleta de dados mais eficaz, com base no método qualitativo de pesquisa, as aulas foram filmadas e posteriormente analisadas, com o objetivo de identificar as características de uma comunidade ecológica, durante o ciclo da tarefa, ou seja mutualismo, comensalismo, competição ou parasitismo, como descrito anteriormente.

Nesta análise, na classe de interação sobre comensalismo, a dicotomia beneficiado x não afetado é substituída por beneficiado x não prejudicado. A 
razão dessa escolha é o pressuposto de que sob a perspectiva da aprendizagem todos os sujeitos envolvidos são afetados.

\section{ANÁLISE E DISCUSSÃO DOS DADOS}

Os dados serão aqui analisados, discutidos e divididos entre as quatro principais características de um sistema ecológico complexo. Primeiramente, abordar-se-á o mutualismo, logo após analisar-se-ão o comensalismo e a competição, sendo por último o parasitismo. Os dados foram coletados durante um ciclo completo da tarefa, no qual os alunos deveriam falar sobre seus sonhos, ambições e conquistas.

\section{Mutualismo}

Durante a tarefa, a qual é realizada em pares, os alunos conversam sobre seus sonhos, ambições e conquistas, e aqui temos o exemplo do mutualismo, quando os dois alunos se beneficiam igualmente da interação. Esse benefício mútuo se dá devido à oportunidade de emergência linguística criada pela interação desses dois alunos, onde cada um terá a sua vez de fazer o relato de forma significativa.

Mais um exemplo foi identificado logo após a tarefa, quando foi dado tempo aos alunos para que planejassem os seus relatórios. Na etapa do planejamento, os alunos, em silêncio mais uma vez, planejam aquilo que vão dizer nos seus relatórios. Nesse momento, o grupo se reorganiza e pode ou não adotar outro comportamento. No caso da aula em questão, o sistema entrou em auto-organização, mas continuou com o mesmo comportamento e mais uma vez identificou-se o mutualismo nessa interação, onde todos os alunos se beneficiam.

\section{Comensalismo}


Durante a pré-tarefa, o professor propõe um exercício, o qual consiste em ouvir pessoas falando sobre seus sonhos, ambições e conquistas, solicitando aos alunos que façam a relação de suas falas com a foto que as ilustram. Neste processo, um dos alunos ainda não havia entendido o significado da palavra "achievement" e questiona o professor, que evita usar tradução e apresenta uma definição com um exemplo pessoal para ilustrar o significado. Um dos alunos oferece a tradução, que esclarece totalmente o significado da palavra. Encontra-se, neste primeiro momento, uma das características de uma comunidade ecológica: o comensalismo. $O$ aluno que está com dúvida é beneficiado pela interação e tanto o professor como o outro aluno que ofereceram ajuda não são prejudicados.

Já na parte final do ciclo da tarefa, mais especificamente no relatório, encontra-se mais um exemplo com comensalismo. Nesta fase os alunos relatam para o grande grupo aquilo que descobriram sobre os sonhos, ambições e conquistas do seu colega. Um aluno usou o pronome possessivo inapropriado. Como o aluno está falando sobre o seu colega, ele deveria usar o pronome "his", mas usa o pronome "your". O professor, para ajudar o aluno na auto-organização do seu sistema pergunta "my dream?" (meu sonho?). O aluno nota que cometeu um erro, pensa e corrige a sua fala, usando o pronome adequado. $O$ aluno se beneficia da interação e o professor, na condição de integrante dessa comunidade ecológica, não é prejudicado.

\section{Competição}

A competição foi identificada no momento em que cada membro desse sistema é prejudicado. Isso ficou evidenciado quando um dos pares termina a tarefa antes do outro e começa a interferir na conversa do outro par. Um dos alunos que já havia terminado sua tarefa com o seu par tenta conversar com um dos alunos dos pares ao lado que ainda não havia terminado a tarefa. Além de interromper a realização da tarefa, ele está falando sobre um assunto 
totalmente diferente. Como o sistema é dinâmico, o membro que não estava fazendo parte da conversa extra faz o seu par voltar ao assunto da tarefa da aula e exclui o terceiro elemento que tenta competir com ele.

\section{Parasitismo}

Na terceira fase do ciclo da tarefa, no relatório, os alunos devem contar para o grande grupo sobre os sonhos, ambições e conquistas de seu colega. 0 professor deixa essa etapa bem clara para que os alunos escutem as histórias com atenção.

Durante esta etapa, pode-se constatar mais uma característica de uma comunidade ecológica, o parasitismo, onde um dos alunos se beneficia e o outro é prejudicado. Um dos alunos faz uma brincadeira, em inglês, sobre o fato de eles terem que escutar o colega com atenção e ele brinca dizendo que vai deixar o colega falando sozinho.

\section{Considerações finais}

Este artigo teve como objetivo analisar os dados fornecidos pela aplicação da Aprendizagem Baseada em Tarefas, mais especificamente o ciclo da tarefa à luz dos conceitos da Linguística Ecológica, e entender o objeto de estudo por meio desse aporte teórico. Também foi objetivo demonstrar as affordances que influenciaram os caminhos tomados pelos aprendizes durante 0 ciclo da tarefa e as características ecológicas que emergiram a partir dessas affordances.

Constatou-se a presença das principais classes de interação ecológica que, de acordo com Paiva (2013), são: mutualismo, comensalismo, competição e parasitismo. A classe mais frequentemente encontrada foi o mutualismo, quando os alunos se beneficiaram igualmente da interação. Isso demonstra a criação de um ambiente propício para a aprendizagem, onde as affordances são criadas para um melhor desenvolvimento linguístico. As classes mais negativas, 
como a competição e o parasitismo, foram vistas em menor número, mas também contribuindo para a criação de um ambiente propício para a aprendizagem.

Tem-se como caminhos futuros de pesquisa a investigação das mesmas características das classes de interações ecológicas, mas em grupos com maior número de alunos, o que tornará possível a comparação com o grupo menor já investigado neste artigo.

\section{Referências}

BORGES, Elaine Ferreira do Vale; PAIVA, Vera Lucia Menezes de Oliveira. Por uma abordagem complexa de ensino de línguas. Linguagem \& Ensino, Pelotas, v. 14, n. 2 , p. 337-356, 2011.

GAIGNOUX, Kelly Cristina M; MOUTINHO, Michell Gadelha. As condições iniciais na construção de uma rede de ideias e reflexões. In: SILVA, Walkyria Magno; BORGES, Elaine Ferreira do Vale (Org.). Complexidade em ambientes de ensino e de aprendizagem de línguas adicionais. Curitiba: CRV, 2016.

GIBSON, James J. The ecological approach to visual perception. 2. ed. Hillsdale: Lawrence Erlbaum Associates, 1986.

KRAMSCH, Claire. Ecological perspectives on foreign language education. Language Teaching, Cambridge, v. 41, n. 3, p. 389-408, 2008.

KRAMSCH, Claire; WHITESIDE, Anne. Language ecology in multilingual settings. Towards a theory of symbolic competence. Applied Linguistics, Oxford, v. 29, n. 4, p. 645-671, 2008.

KRASHEN, Stephen D. Principles and practice in second language acquisition. Oxford: Pergamon, 1982.

KUMARAVADIVELU, B. Understanding language teaching: from method to postmethod. Londres: Lawrence Erlbaum Associates, 2006.

LARSEN-FREEMAN, Diane. Chaos/complexity science and second language acquisition. Annual Review of Applied Linguistics, v. 18, n. 2, p. 141-165, 1997. 
LARSEN-FREEMAN, Diane; CAMERON, Lynne. Complex systems and applied linguistics. Oxford: Oxford University Press, 2008.

LEFFA, Vilson José. Ensino de línguas: passado, presente e futuro. Pelotas: Educat, 2003.

LONG, M. H. A role for instruction in second language acquisition: task-based language training. In: HYLTENSTAM, Kenneth; PIENEMANN, Manfred (Ed.). Modeling and assessing second language development. Clevedon: Miltilingual Matters, 1985. p. 77-99.

LOPES JÚNIOR, Juarez Aloizio. Aprendizagem da língua inglesa como segunda língua baseada em tarefas: uma proposta de trabalho com ciclo complexo. 2014. Dissertação (Mestrado em Letras) - Centro de Letras e Comunicação, Universidade Federal de Pelotas, Pelotas, 2014.

NUNAN, David. An organic approach to grammar teaching. Hong Kong Journal of Applied Linguistics, Hong Kong, v. 1, p. 65-86, 1996.

ODELL, James. Agents and emergence. Distributed Computing, Berlin, p. 4550, oct. 1998. Disponível em: <http://www.jamesodell.com/DC9810JO.pdf>. Acesso em: 31 Out. 2016.

PAIVA, Vera Lúcia Menezes de Oliveira. Aquisição de segunda língua. São Paulo: Parábola, 2014.

PAIVA, Vera Lúcia Menezes de Oliveira. Interação e aquisição de segunda língua: uma perspectiva ecológica In: GERHARDT, Ana Flávia Lopes Magela; AMORIM, Marcel Álvaro de; CARVALHO, Álvaro Monteiro (Org.). Linguística aplicada e ensino de língua e literatura. Campinas: Pontes Editores, 2013. p. 187-205

PRABHU, N. S. Second language pedagogy. Oxford: Oxford University Press, 1987.

SKEHAN, Peter. A cognitive approach to language learning. Oxford: Oxford University Press, 1998.

SKEHAN, Peter. Review article: task-based instruction. Language Teaching Research, Pennsylvania, v. 36, p. 1-14, 2003.

VAN LIER, L. From input to affordance: social-interactive learning from an ecological perspective. In: LANTOLF, James (Ed.). Sociocultural theory and second language learning. New York: Oxford University Press, 2000. p. 245259. 
VAN LIER, Leo. The ecology and semiotics of language learning: a sociocultural perspective. Monterey: Kluwer Academic Publishers, 2004.

VAN LIER, Leo. The ecology of language learning: practice to theory, theory to practice. Procedia: social and behavioral sciences, [S. I.], v. 3, p. 2-6, 2010.

WATSON-GEGEO, Karen Ann. Ethnography in ESL: defining the essentials. In: BROWN, Douglas; GONZO, Suzan T. Readings on second language acquisition. Englewood Cliffs, NJ: Prentice Hall, 1995. p. 36-54.

WILLIS, Dave; WILLIS, Jane (Ed.). Doing task-based teaching. Oxford: Oxford University Press, 2007.

WILLIS, Jane. A framework for task-based learning. Harlow: Longman, 1996. 